\title{
Verhandlungskunst: Mit leichter Hand das Schaf wegführen
}

\section{Werner Bauer}

Dr. med., Mitglied der Redaktion

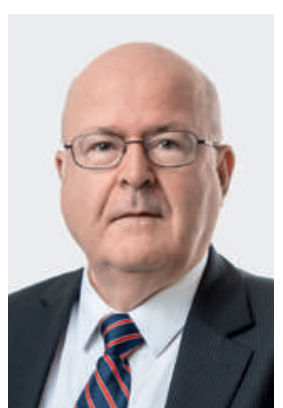

Verhandeln ist heute eine tägliche Aufgabe der Verantwortungsträger in allen möglichen Sparten. Auch im Gesundheitswesen gehören lange, oft allzu lange Sitzungen zum Alltag. Seien es spitalinterne Verhandlungen, seien es Verhandlungen von Ärztevertretern mit Versicherern, staatlichen Stellen oder anderen Institutionen, seien es Diskussionen innerhalb der Ärzteschaft oder mit anderen Gesundheitsberufen, es geht um Positionen, Projekte, Honorare, Finanzierungen, Regulierungen, Strukturen oder Richtlinien. Im Moment erleben wir hochintensive Verhandlungskaskaden im Zusammenhang mit der Revision des ambulanten Arzttarifs.

Sind Ärzte kompetent im Verhandeln, weil sie Ärzte sind und weil Ärzte gar manches können?

Ich habe noch den Ausklang der Zeit erlebt, als zum Beispiel in den Bezirkskrankenkassen die Vorstandssitzungen am Feierabend stattfanden und der Delegierte der Ärzteschaft erst nach dem letzten Hausbesuch eintraf. Die Kassenvertreter waren Honoratioren der Region vom Posthalter bis zum Verwalter der örtlichen Sparkasse. Alle waren im Nebenamt tätig, eher konsensorientiert, und die ärztlichen Vertreter konnten auf Grund ihrer Kenntnisse, ihrer Erfahrung im Argumentieren und ihrer Position in Gemeinde und Region ihre zentralen Anliegen meist ohne Probleme wirkungsvoll vertreten und Beschlüsse entsprechend beeinflussen.

Die Zeiten haben sich geändert. Die kleinen Krankenkassen haben sich in Grosskassen hineinfusioniert, die Sitzungen finden zur regulären Arbeitszeit statt und die Gegenüber der Ärzte sind nicht mehr wohlwollende Posthalter und Sparkassenverwalter, sondern im Falle der Krankenkassen primär ökonomisch denkende, taktisch vorbereitete, auf ihre Interessen verpflichtete Mitarbeiter. Dasselbe gilt für die Verhandlungspartner der Ärzte in Spitälern, bei staatlichen Stellen oder vielen anderen Organisationen.

Die Verhandlungstechnik wird damit zu einer Disziplin, die auch für das erfolgreiche Wahrnehmen ärztlicher Mandate mitentscheidend ist. Es gibt dazu eine umfangreiche Literatur und ein reichliches Kursangebot. Als Grundelemente des Verhandelns werden auf einer einschlägigen Website (www.rhetorik.ch) die solide Fachkenntnis, die Logik, die Überzeugungskraft und das psychologische Verständnis definiert. «Gewinnen ohne zu siegen" umschreibt dabei ein Verhandlungsziel, welches beiden Parteien ermöglichen soll, Verhandlungen mit einem guten Gefühl zu verlassen, was die Voraussetzung für eine wirklich akzeptierte, längerfristige Lösung ist. Zur Verhandlungskunst: In diesem Zusammenhang erinnere ich mich an einen Vortrag und an zwei Bücher von Harro von Senger, der Professor für Sinologie in Freiburg im Breisgau war: 36 Strategeme für Manager [1] und Die Kunst der List. Strategeme durchschauen und anwenden [2] Das Wort «Strategem» wird zwar oft vereinfacht als Fremdwort für «List» verstanden, doch widerspiegeln die Strategeme eine Listtechnik im positiven Sinn, die viel mehr auf Klugheit und Findigkeit als auf Trick und Täuschung beruht. Während der englische Aufklärer John Locke die List als «Affe der Weisheit» bezeichnete, sei sie für die Chinesen ein Produkt der Weisheit, des Intellekts. Im richtigen Moment eingesetzt kann ein Strategem entscheidend sein, um eine Verhandlung oder eine Aktion in die gewünschte Richtung zu steuern. Ihre Kenntnis kann grundsätzlich beiden Seiten den Blick für Manipulationen schärfen und einer akzeptablen Problemlösung dienen. Es gibt verschiedene Strategem-Kategorien (für eine Vertiefung sei auf die Publikationen von Harro von Senger verwiesen, aus denen ich zitiere), die je nach der Stärke der eigenen Position und dem Stand von Verhandlungen zur Anwendung kommen können.

- Einen dürren Baum mit künstlichen Blumen schmücken (Imponier-Strategem).

- Den Tiger vom Berg in die Ebene locken (IsolationsStrategem).

- Die Akazie scheltend auf den Maulbeerbaum zeigen (Strategem der indirekten Kritik).

- Mit leichter Hand das Schaf wegführen (ständige Bereitschaft, Chancen auszuwerten).

- Will man etwas fangen, muss man es zunächst loslassen (Strategem mit Weitblick).

- Die Feuersbrunst am gegenüberliegenden Ufer beobachten (Heraushalte-Strategem).

Verhandlungstechnik und Verhandlungskunst sind jenseits der zu lösenden Sachprobleme immer wieder die entscheidenden Elemente des Erfolgs - auch für Ärzte: Keinem in die Ebene gelockten Tiger vom Berg darf es hinter einem dürren Baum mit künstlichen Blumen gelingen, mit leichter Hand das Schaf wegzuführen! 